\title{
To Die at Home or to End Life in an Institution
}

\author{
Liv Wergeland Sørbye ${ }^{1 *}$, Simen A. Steindal1,2, Svein Lyngroth ${ }^{3}$ \\ ${ }^{1}$ Institute of Nursing and Health, Diakonhjemmet University College, Oslo, Norway \\ ${ }^{2}$ Palliative Care Unit, Department of Oncology, Oslo University Hospital, Oslo, Norway \\ ${ }^{3}$ Agenda Kaupang, Evaluation \& Assessment, Bærum, Norway \\ Email: soerbye@diakonhjemmet.no
}

Received 27 April 2015; accepted 19 June 2015; published 24 June 2015

Copyright (C) 2015 by authors and Scientific Research Publishing Inc.

This work is licensed under the Creative Commons Attribution International License (CC BY). http://creativecommons.org/licenses/by/4.0/

(c) () Open Access

\begin{abstract}
In the Western world, $60 \%-80 \%$ of all deaths occur in an institution. This study aimed to determine the main causes for the low proportion of deaths at home in Norway. A retrospective cohort study was conducted in six Norwegian municipalities. The study employed official statistics and structured interviews with key staff individuals (spring 2012). We included 41 individuals that received palliative home care; 21 died at home. The rate of deaths at home may be increased by an acceptance of death and confidence that home is a good, safe place to die. This study showed how challenging it was for the family and health personnel to be a fellow Pellegrino in the last steps of life. However, when physical distress is under control, and when a dying patient and his significant other genuinely wish for death at home, it is necessary to control physical distress. Greater holistic well-being may then be achieved at home than in the hospital.
\end{abstract}

\section{Keywords}

Home Care Services, Attitude towards Death, Retrospective Cohort Studyomponent

\section{Introduction}

The concept of home evokes several associations. "Longing for home" or "the feeling of home" has become a central part of our everyday understanding of the notion of home [1] [2]. In the early 20th century, a romantic concept of home emerged. Three important phenomena were identified as domestic constructs: privacy, identity, and familiarity [3]. Security is another value that people associate with the concept of home. Here, they could be sheltered from stress that might worsen their condition [4]. At home, people feel like themselves; there is no

"Corresponding author. 
need to show off, and one may dress comfortably. Home could be a "secure base" when death is approaching [5].

The home has always been a place of caring. Currently, the quality of available housing and technical equipment is sufficiently advanced to enable people with severe impairments to manage at home, even when they live alone. Medical technology has made it possible for patients with multiple diseases to be treated in their own home due to integrated care.

In the mid1970s, the Hospice philosophy spread from England to the rest of Europe. The idea of palliative home care was created. The ability to die at home could be a quality indicator of optimal palliative care. In the Western world, $60 \%$ - $80 \%$ of all deaths occur in an institution. Currently, in Norway, education programs, care models, ambulatory, multidisciplinary, palliative and care teams, and standards for palliative care are well established. However, only $14 \%$ of Norwegians die at home, including unaccepted deaths. The Norwegian welfare model supports inhabitants with well-structured community care. Home nursing may be available 24 hour per day. People that choose to spend their last days of life in their own home may receive help from a palliative care team. However, most often, individuals with terminal illnesses are transferred to an institution when their health condition deteriorates and death seems imminent. In Norway, $46 \%$ of deaths occur in a nursing home, $34 \%$ in an acute care hospital, $14 \%$ at home, $4 \%$ in other places, and $2 \%$ in unknown places [6]. The percentage of all cancer deaths that occur at home varies in different European countries, from $12.8 \%$ in Norway to $45.4 \%$ in the Netherlands [7]. There is conflicting evidence about the benefits of home care at the end of life for individuals with terminal illnesses, but recent research has suggested that holistic well-being may be felt more strongly at home than in an institution [8]. The current study aims to describe the organization of home services that provides end of life care and to discuss the main causes for the low rate of home deaths in Norway.

\section{Methods}

\subsection{Design, Sample and Settings}

This descriptive study was based on national and local statistics in the municipalities and structured interviews in the municipalities. The intention was to reflect on the situation to individual families in light of official statistics. We conducted a secondary data analysis on a retrospective survey with key individuals of the home care staff (spring 2012). Official statistics on Norwegian society (SSB) provided non-identifiable data for the time period of 2006-2010 for all municipalities in Norway [9].

Six municipalities were included. In each group, patients with cancer had died at home; in some municipalities, this number represented over $20 \%$, and in others, it represented less than $10 \%$ of the population. Both rural and urban municipalities were included. At each site, the study survey was embedded within the home care management routine. Written information about the study was provided. The research team made arrangements with the coordinators responsible for each individual home-based service to ensure a common understanding among the staff and/or employees. The survey provided an overview of each municipality's use of resources over the last six months of life for each individual that died. This data was compared to current treatment guidelines to obtain a picture of the physical workflow and the information recorded throughout the supply chain, including any decision points.

The survey included 41 individuals that received palliative care, the time from when life-prolonging treatment no longer should be continued until the moment of death. The key nurse responsible for each patient was interviewed. A structured guideline was given out ahead of time to ensure that facts were accurate. The following data were collected: age, living conditions, patient activity, relatives, commitment from the family, home care services, doctor, physical therapy, and any short-term stays at a hospital, nursing home, hospice or palliative care unit and the reason for transfer to an institution in the last days of life. Nurses that held key positions in the municipality care systems were interviewed to describe the organization and working methods related to nursing and care services. The minutes of the interviews were sent to the participants for perusal. Non-identifiable data for patients and staff were collected. Information that nurses provided about the patients were de-identified and cases were not connected to the name of the municipality.

\subsection{Statistical Analysis}

Patient data were retrieved from Statistics Norway, and retrospective care data was retrieved from the homecare 
organizations in the six municipalities. A structured questionnaire was used for the interviews with the home care nurses. The responses were compiled in Excel files. Data analysis was performed using Statistical Package for Social Science version 21 (SPSS Inc., Chicago, IL, USA). Here descriptive statistics are presented in tables. Cross-tabulation and chi-square tests were used to analyze different between groups (confidence intervals, 95\%).

\subsection{Ethics}

The study design and data collection did not require approval from the Regional Committee of Medicine and Health [10]. We did not use medical record data or any other information connected to personal identification. The project was approved by the Local Government Employer and Interest Organization. A key individual in each of the participating municipalities was responsible for the delivery of de-identified data. The first author was a part of the research team.

\section{Results}

\subsection{General Population Statistics}

The six municipalities included in this study had 8522 to 114,489 total inhabitants. The distribution of deaths that occurred at home and at other sites for the entire sample was similar to the distribution observed in all of Norway during the given study period (Table 1).

\subsection{Cohort Home Care Analyses}

Next, we looked at characteristics of patients, place of death and determined the resources required for caring for individuals during the last 6 months of life in a sample of 41 individuals (Table 2 and Table 3). This cohort included 25 males and 16 females, with a mean age of 73.4 years old. Nearly half lived alone, and most had cancer. A significantly larger proportion of the males than females died at home $(\mathrm{p}<0.01)$. There was no significant difference in the percentage of home deaths between those who lived with a spouse and those who lived alone.

During the palliative phase, about half the patients that died at home (52\%) had been admitted to a hospital one or more times, but none had been to a nursing home or hospice unit. Patients that died in an institution had, all except one, stayed in an institution one or more times before they died. The palliative phase, regardless of place of death, was provided for individuals in the home setting. Table 3 presents the average length of stay at different levels of care during the palliative phase.

\subsection{Main Reasons for Transferring a Dying Patient to an Institution}

The average length of palliative care was 54 days for the 22 patients that lived with their spouse and 46 days for the 19 patients that lived alone. The four that died in a hospice or hospice unit, were all women and lived alone. In the municipalities with a high proportion of home deaths, three patients were transferred to an institution during the last three days, while six patients in the municipalities with a low proportion of home deaths. The analysis of the data retrieved from interviews with nurses identified several reasons for transfer to an institution in the

Table 1. Distributions of all deaths that occurred at home in the sample municipalities. Period 2006-2010. N = Total number of inhabitants, nearest 500, death in \% (6).

\begin{tabular}{|c|c|c|c|c|c|c|c|c|}
\hline \multirow{4}{*}{ Place of death } & \multicolumn{3}{|c|}{$\begin{array}{l}\text { Municipalities with low rates of } \\
\text { deaths at home }(<10 \%)\end{array}$} & \multicolumn{3}{|c|}{$\begin{array}{l}\text { Municipalities with high rates of } \\
\text { deaths at home }(>20 \%)\end{array}$} & \multirow{2}{*}{$\begin{array}{l}\text { Average for } \\
\text { our sample }\end{array}$} & \multirow{2}{*}{$\begin{array}{l}\text { Average for } \\
\text { Norway }\end{array}$} \\
\hline & 1 & 2 & 3 & 4 & 5 & 6 & & \\
\hline & $\mathrm{N}$ & $\mathrm{N}$ & $\mathrm{N}$ & $\mathrm{N}$ & $\mathrm{N}$ & $\mathrm{N}$ & $\mathrm{N}$ & $\mathrm{N}$ \\
\hline & 20,500 & 30,000 & 112,500 & 2500 & 81,000 & 21,500 & 238,000 & $4.850,000$ \\
\hline Hospital & 64 & 67 & 47 & 28 & 47 & 30 & 48 & 48 \\
\hline Nursing home & 30 & 28 & 48 & 50 & 30 & 40 & 39 & 40 \\
\hline Home/outside institution & 7 & 5 & 6 & 22 & 23 & 29 & 13 & 12 \\
\hline
\end{tabular}


Table 2. Characteristics of the study sample; $\mathrm{N}=41$ individuals that desired to die at home.

\begin{tabular}{cccccc}
\hline \multirow{2}{*}{ Characteristics } & N (\%) & \multicolumn{4}{c}{ Place of death, N (\%) } \\
\cline { 3 - 5 } & & Home & Nursing home & Hospital & Hospice unit \\
Male & $25(61)$ & $17(81)$ & $5(63)$ & $3(11)$ & 0 \\
Female & $16(39)$ & $4(19)$ & $3(37)$ & $6(89)$ & $3(100)$ \\
Age, years; mean/range & $73.4(40-95)$ & $73.6(55-95)$ & $78(50-95)$ & $71.1(40-90)$ & $61.7(60-65)$ \\
Over $\geq 75$ years old & $23 / 41(56)$ & $13 / 21(62)$ & $6 / 8(75)$ & $4 / 9(44)$ & 0 \\
Lived alone & $19 / 41(46)$ & $10 / 21(48)$ & $3 / 8(38)$ & $3 / 9(33)$ & $3 / 3(100)$ \\
Cancer & $37 / 41(90)$ & $20 / 21(95)$ & $6 / 8(75)$ & $8 / 9(89)$ & $3 / 3(100)$ \\
Total & $41(100)$ & $21(51)$ & $8(20)$ & $9(22)$ & $3(7)$ \\
\hline
\end{tabular}

${ }^{\mathrm{a}} 56 \%$ lived with a spouse.

Table 3. Average length of stay at different levels of care during the palliative phase; $\mathrm{N}=41$.

\begin{tabular}{|c|c|c|c|c|c|c|}
\hline \multirow{2}{*}{ Place of Care } & \multirow{2}{*}{$\begin{array}{c}\text { Number of } \\
\text { Patients N (\%) }\end{array}$} & \multicolumn{4}{|c|}{ Average length of stay: Days mean (range) } & \multirow{2}{*}{$\begin{array}{c}\text { Average fraction } \\
\text { of total palliative } \\
\text { care, }(\%)\end{array}$} \\
\hline & & Mean & Median & Mode & Standard deviation & \\
\hline Home & $41(100)$ & 54 & 33 & $0^{\mathrm{a}}$ & 51.7 & $54 / 67(80)$ \\
\hline Hospital & $24(59)$ & 5.3 & 3 & 0 & 6.9 & $5.3 / 67(8)$ \\
\hline Nursing home & $11(27)$ & 3.7 & - & - & 7.7 & $3.7 / 67$ (5.6) \\
\hline Hospice & $3(7)$ & 3.7 & - & - & 15.0 & $3.7 / 67(5.6)$ \\
\hline Total Care & $41(100)$ & 67.5 & 45 & $180^{\mathrm{a}}$ & 54.2 & 67/67 (99) \\
\hline
\end{tabular}

${ }^{\mathrm{a}}$ Multiple modes exist. The smallest value is shown.

terminal phase: rapid deterioration, heavy care burden and required improved symptom management for the last days of life due to pain, shortness of breath and anxiety (Table 4).

\subsection{Main Concerns for Dying at Home}

This study presents 21 patients who died at home, ten from municipalities with less than $10 \%$ home deaths and eleven from municipalities more than $20 \%$ of home deaths. All of the patients except one had a cancer diagnosis. The data revealed a strong commitment from the family. In some cases the family only needed assistance for nursing procedures; they wanted to carry out the caring themselves. Patients living by themselves, had next of kin that actively contributed to fulfill the patients wish to stay in their own home. In all the municipalities they had possibilities to increase the amount of nursing care hours as much as needed. The characteristics of the last weeks of life in municipalities with a high proportion of home deaths revealed good organization of integrated care and a high frequency of drug pumps.

\section{Discussion}

This study investigated patients that wished to receive palliative care at home. We found that, when the time of death was apparent (the terminal stage), the commitment to die at home diminished. Further investigation revealed that the decision to transfer the patient to an institution was based on being a female, rapid deterioration, heavy care burden and inadequate symptom control.

Norway has a well-organized palliative care system that comprises home care, palliative care teams, and staff with post graduate degrees in cancer or palliative care. The goal of palliative care has been to enhance the ability of patients to stay at home for a long as possible, rather than to enable dying at home. Long-term care institutions have a long tradition of serving as a keystone in the Nordic welfare model. This might explain the low 
Table 4. Main reasons for transferring dying patients from home to an institution $(\mathrm{N}=20)$.

\begin{tabular}{|c|c|c|c|c|c|c|c|}
\hline Sex & Age $^{*}$ & Household & Disease & $\begin{array}{l}\text { No LPT }^{\text {a }} \\
\text { (days) }\end{array}$ & Reason for transfer & Place of death & Days to death \\
\hline \multicolumn{8}{|c|}{ Patients from municipalities with a low proportion of home death } \\
\hline $\mathrm{F}$ & 80 & Spouse & Breast cancer & 40 & Nausea, pain & Hospital (ED) ${ }^{\mathrm{c}}$ & 1 \\
\hline $\mathrm{F}$ & 40 & Alone & Breast cancer & 68 & Pneumonia & Hospital & 5 \\
\hline $\mathrm{F}$ & 70 & Spouse & Unsp. Cancer $^{\mathrm{a}}$ & 49 & Ascites & Hospital & 1 \\
\hline $\mathrm{F}$ & 70 & Spouse & Breast cancer & 15 & Family felt uncomfortable & Nursing home & 1 \\
\hline M & 90 & Spouse & Gastric cancer & 20 & Anxiety & Hospital & 3 \\
\hline $\mathrm{F}$ & 85 & Alone & Meningitt & 9 & Pain and Anxiety & Hospital (PU) ${ }^{d}$ & 1 \\
\hline $\mathrm{F}$ & 65 & Alone & Unsp. Cancer ${ }^{\mathrm{b}}$ & 77 & Anemia, dehydration, pain & Hospice & 24 \\
\hline $\mathrm{F}$ & 60 & Alone & Unsp. Cancer ${ }^{\mathrm{b}}$ & 103 & Respiratory distress and pain & Hospice & 22 \\
\hline $\mathrm{F}$ & 60 & Alone & Cancer abdomen & 165 & Pain & Hospice & 10 \\
\hline $\mathrm{M}$ & 80 & Alone & Unsp. Cancer ${ }^{\mathrm{b}}$ & 22 & Lack of organization & Nursing home & 3 \\
\hline \multicolumn{8}{|c|}{ Patients from municipalities with a high proportion of home death } \\
\hline M & 60 & Alone & Lung cancer & 24 & Constipation, pain & Hospital (ED) ${ }^{\mathrm{c}}$ & 1 \\
\hline M & 70 & Spouse & Gastric cancer & 68 & Anxiety, Respiratory distress & Hospital & 30 \\
\hline $\mathrm{F}$ & 70 & Alone & Lung cancer & 44 & Respiratory distress & Hospital & 4 \\
\hline $\mathrm{F}$ & 75 & Alone & Breast cancer & 18 & Respiratory distress. & Hospital & 1 \\
\hline M & 95 & Spouse & Multi-organ failure & 31 & Respiratory distress & Nursing home & 20 \\
\hline $\mathrm{M}$ & 80 & Spouse & Bladder cancer & 20 & Pain & Nursing home & 6 \\
\hline M & 85 & Spouse & Unsp. Cancer & 125 & Functioning decline & Nursing home & 21 \\
\hline $\mathrm{F}$ & 85 & Alone & Multi organ decline & 180 & Functioning decline & Nursing home & 7 \\
\hline $\mathrm{F}$ & 80 & Alone & Lung cancer & 25 & Functioning decline & Nursing home & 19 \\
\hline $\mathrm{M}$ & 50 & Spouse & Unsp. Cancer $^{\mathrm{b}}$ & 180 & Palliation & Nursing home & 1 \\
\hline
\end{tabular}

${ }^{\mathrm{a}}$ No LPT: No life-prolonging treatment; this is the duration of palliative care, ${ }^{\mathrm{b}}$ Unsp. cancer: unspecified cancer, ${ }^{\mathrm{c}} \mathrm{ED}$ : Emergency department, ${ }^{\mathrm{d}}$ Palliative care unit.

\section{Fact box}

Low portion of home deaths $(\mathrm{N}=10)$

- Some home care teams struggled to alleviate burdensome symptoms Only one of ten patients had a drug pump

- The home care teams experienced some times little support from medical staff in the municipality

- Home care teams often used advices from the hospital palliative team for pain management

- Problems with technical supply. A hospital bed arrived two days before death, and could not be moved up the stairs

- One home care team expressed that they should have given the next of kin more emotional support
High portion of home deaths $(\mathrm{N}=11)$

- Good pain management. Six of eleven patients had a drug pumpSame caregivers contributed to security

- Good organised integrated care

- Home care teams got support from the cancer coordinator and had close contact with the general practitioner

- Lack of adequate equipment were not mention

- Home care teams expressed confidence in caring for the dying persons and their families 
proportion of patients with cancer that died at home in Norway (11.8\%) compared to the proportion observed in the Netherlands (45.4\%) [7]. The basis of the Nordic welfare model has been described with three essential features: a comprehensive social policy, an institutionalized social entitlement principle (social rights), and solidaristic, universalist social legislation [11]. In the Nordic countries, in contrast to many other countries, adult children have no legal obligation to provide care or financial support for their parents [12]. Researchers emphasized that the formal health care systems of Nordic countries function well. Anyone may apply for health care, but the administrative staff in the municipalities must assess the applications to determine the amount of assistance to provide. The municipalities are primarily responsible for providing both institutional and non-institutional services [13] [14]. However, due to the increasing proportion of older individuals, the lack of qualified staff and funding could reduce the amount of individual care available. Moreover, the Nordic welfare model has created an unwanted boomerang effect, because the family is currently considered less important than it was traditionally. Recently, it has been questioned whether the degree of de-familiarization might create risk situations for some people [15]. In the current study, the decision to die at home did not depend on an individual's living arrangement. However, the grown-up children of dying individuals were willing to provide support for a limited time period, with assistance from the home care team.

In the current study, cancer was the main cause of death. In England, patients with cancer were denied a last wish to die at home, due to a shortage of nurses. Among the patients that expressed a preference, the majority preferred to die at home (81\%) [16]. In Norway, $12 \%$ of patients with cancer died at home, compared to $30 \%$ in England [9] [17]. Hospitals remain the most common place of death for patients with cancer. A research team analyzed all cancer deaths in England, based on data acquired by the Office for National Statistics during 19932010 [18]. They concluded that more effort was needed to reduce hospital deaths; for example, more support should be given to individuals that live alone. Those that lived alone received, on average, less assistance than those that lived with others (10 hours versus15 hours a week) [18]. A study of individuals with terminal illnesses in the municipalities revealed that patients with informal caregivers appeared to require twice as many visits from the home care team than the group of patients without informal caregivers [19] [20]. An interview study with older people with cancer found that the presence of a co-resident caregiver influenced how much knowledge the patient had about the support services available. However, even when both the patient and the family choose home care, it may turn out to be an unrealistic choice [21].

In our material, living alone was not a reason for transfer to an institution, but females were transferred more frequently than males. This result was consistent with general Norwegian population statistics and findings from other studies, women died less frequently at home than men. They emphasized that it would be important to establish whether female patients or their spouse might need a different type of support from that required by male patients or their female caregivers. Traditionally, females cope better with practical caring tasks than men; thus, female caregivers may experience less stress than males in caring for a spouse [22] [23]. Two important factors that strengthened the concern for dying at home were [1] the ability of the home care team to provide adequate assistance for both the patient and family and [2] a strong commitment from the family.

Families that received integrated care lead by a coordinator, relaxed better in a home care setting. General practitioners had a central part. Families expressed that being able to meet the same caregivers contributed to security. Most of the patients received less than 20 hours per week from the home care service, but the family felt free to ask for extension of care on "bad days". Professional help like close contact with the hospital staff, and substantial assistance from specialist services reduced anxiety and distress. Adequate symptom control was essential in order to be able to remain at home. The municipalities with a high proportion of home death could offer integrated care and they administrated drug pumps for pain relief.

A systematic review of the practical information needed by informal caregivers in palliative home care revealed that informal caregivers acquired practical nursing skills [24]. Moreover, they recommended that homebased palliative care services should be aware of that fact. In the current study, a heavy care burden was a central reason for not staying at home. However, the municipalities emphasized that they could extend the amount of home care support, when requested by the family. We found that few patients received more than 20 hours per week from the home care service, including those that required cancer nursing.

In considering the economic cost of palliative care, we found that the municipal expenditure per individual in municipalities with a high proportion of home deaths was lower than that of municipalities with a low proportion of home deaths. The municipal employees in regions with a high proportion of home deaths reported being highly satisfied with the cooperation shown by the patients, families, and doctors. They could focus on the work 
that most required the expertise of home services in caring for patients in the palliative phase [9].

In the current study, the intention of home care was to allow patients to die at home. However, 20 (49\%) patients died in an institution. Other studies confirmed our findings that dying patients were transported to an institution to provide a different level of care during the last days of life. In one study they screened patients in palliative care to determine whether high level in-service care was necessary during the last two weeks of life. For example, at the end of life, it would be considered poor care quality to transfer an individual to an institution for a life-prolonging treatment, because it would expose the patient to new, stressful situations [25]. However, it might be necessary to transfer a highly distressed patient to an institution for symptom relief and care. It is important to emphasize that the community-based services must be adequately trained to prevent unnecessary hospital admissions of patients with terminal illnesses [26]. In the majority of cases, the family doctor, in collaboration with the homecare team, should be able to alleviate burdensome symptoms at the end of life. The Norwegian Coordinator Reform transferred duties from the hospitals to the municipalities. The main principle should be "The best effective care level"; however, at the end of life, patients should not occupy hospital beds [27]. In the current study, there was great variation between the selected municipalities in how they worked with municipal general practitioners, in terms of cooperation and supervision. Some municipalities reported that working with GPs was satisfactory. Research studies found that downsizing hospitals led to fewer deaths in the hospitals and more home deaths. There was no corresponding increase in ambulatory medical care visits, but the family doctor did visit patients more often [28]. Dying patients and their families need to know that they will receive assistance from health care workers trained in providing palliative care at home. In the current study, the patients were not transferred to an institution for life-prolonging treatment, but for symptom relief and more sophisticated care. The home care team showed over and over that they had the skills and competence needed for adequate palliative care.

A retrospective study about healthcare restructuring and family doctor care for individuals that died of cancer gave important results. Families confirmed that pain and nausea were well-controlled. At the end of life, the concept of well-being was a better indicator than the quality of life. Well-being was highly correlated with the Symptom Distress Score [29]. In the current study, anxiety and distress in both the family and the dying patient comprised a reason to transfer the patient to an institution. Data indicated that impending death was difficult to face. It would be important to emphasize that adaptation to advanced cancer differs from adaptation to early stage cancer [30]. In the current study, the number of years that patients lived with a cancer diagnosis varied. We retrospectively followed the palliative phase, but in some cases, the patients or the family may not have been ready to accept that death was approaching. Often, healthcare workers at hospitals failed to communicate that death was imminent. Researches stated that knowledge of their medical prognosis enabled patients with terminal illnesses to make decisions about treatments, to plan end-of-life care, and to achieve acceptance of death [31].

The concept of death preparedness has been analyzed. The author concluded that more research should focus on the concept of death preparedness and the process of dying to explore areas that might facilitate advance directive planning and acceptance of palliative measures for chronic health conditions [32]. Researcher emphasized that, despite advances in technology and medicine, death remains an immutable certainty [33]. In their study of patients with advanced cancer that received palliative care, they found that social support was positively associated with acceptance of death. In the Norwegian health care curriculum, ethical concerns are important, but spirituality and religious questions are seldom verbalized. The transfer to a higher level of medical expertise might be an existential challenge, the courage to accept death as a final option, rather than a shortcoming of the health care service at the municipality level.

Limitations and strengths: We chose to use national statistics and a retrospective design to study the characteristics and care history of patients that received palliative care. The national statistics on place of death should be valid and reliable. The municipalities that we selected were representative of Norwegian municipalities with high and low percentages of deaths at home. The advantage of using this method is that we knew the outcome in advance. The mapping and selection of patients were complicated. Information had to be entered manually, due to the different computer-based technical systems in different municipalities.

The municipalities had, to the greatest extent possible, attempted to select a random sample. Nonetheless, it was challenging to ensure random selection, because we wanted to analyze appropriate cases, and some cases were difficult to analyze, for practical purposes. For example, the interview had to be conducted with nurses that had knowledge of the patient. Sometimes they could not check the information, because the included patient records had been removed after their death. Also, it is difficult to recruit a representative sample prospectively; 
therefore, we used a retrospective design, which was less time consuming. Another weakness of the study was that the researchers had little control over the data; therefore, the accuracy of the data relied on the reports provided by municipal employees.

\section{Conclusion}

The results from the six municipalities included in this study showed that it was possible to organize an acceptable death care at home when those on the health care team shared a common philosophy. Confidence in the philosophy that home was the best place to die decreased when death became imminent. Insufficient terminal care, a heavy care burden, a female patient, and anxiety and distress were the most common factors that led to a transfer to an institution. Early contact between the family and the home care team or the cancer coordinator could prevent unnecessary admission of patients with terminal illnesses to an institution. The rate of home deaths may be increased by encouraging an acceptance of death and confidence that home is a good, safe place to die. In the current study, we learned how challenging it was for the family and the health personnel to be bedside at the last steps of life. It may be possible to achieve greater holistic well-being at home than in a hospital. Essential factors are that the dying patient and the significant other genuinely wish for a death at home, and physical distress has to be under control.

\section{Acknowledgements}

We would like to thank the Norwegian Association of Local and Regional Authorities for providing the opportunity to study death in the municipalities. This association is the only employers' association and interest organization for municipalities, counties, and local public enterprises in Norway. Thanks to Finn Arthur Forstrøm at Agenda Kaupang, Evaluation \& Assessment, Bærum, Norway, for processing and analyzing the national statistics of Norway.

\section{Conflict of Interest Statement}

We do not have any conflict of interest with any issue discussed in this article.

\section{References}

[1] Moore, J. (2000) Placing Home in Context. Journal of Environmental Psychology, 20, 207-217. http://dx.doi.org/10.1006/jevp.2000.0178

[2] Lantz, G. (1996) Människan, hemmet och tingen. In Gaunt, D. and Lantz, G., Eds., Hemmet i vården-vården $i$ hemmet (Home in Nursing-Nursing at Home). Liber forlag, Stockholm, 1-64.

[3] Somerville, P. (1997) The Social Construction of Home. Journal of Architectural and Planning Research, 14, $226-245$.

[4] Heggdal, K. (2003) En grunnleggende prosess for mestring av kronisk sykdom. Chronic illness. The Process of Embodied Knowledging. Universiteteti Bergen. Seksjon for sykepleievitenskap. Department of Nursing, Bergen.

[5] Milberg, A., Wahlberg, R., Jakobsson, M., Olsson, E. C., Olsson, M. and Friedrichsen, M. (2011) What Is a "Secure Base” When Death Is Approaching? A Study Applying Attachment Theory to Adult Patients' and Family Members' Experiences of Palliative Home Care. Psycho-Oncology, 21, 886-895. http://dx.doi.org/10.1002/pon.1982

[6] Statistics Norway (2012) Causes of Death, 2011. https://www.ssb.no/statistikkbanken/SelectVarVal/Define.asp?MainTable=Dodssted\&KortNavnWeb=dodsarsak\&PLa nguage $=0 \&$ checked=true

[7] Cohen, J., Bilsen, J., Addington-Hall, J., Lofmark, R., Miccinesi, G., Kaasa, S., Onwuteaka-Philipsen, B. and Deliens, L. (2008) Population-Based Study of Dying in Hospital in Six European Countries. Palliative Medicine, 22, $702-710$. http://dx.doi.org/10.1177/0269216308092285

[8] Higginson, I., Sarmento, V., Calanzani, N., Benalia, H. and Gomes, B. (2013) Dying at Home-Is It Better: A Narrative Appraisal of the State of the Science.Palliative Medicine, 27, 918-924.

[9] The Municipal Sector Organization (KS) (2012) En naturlig avslutning på livet (A Natural End of Life). Agenda/ Kauang (Ed.) http://www.ks.no/contentassets/84913fec5e104276a01dccd832e6fade/r7543-ks-en-naturlig-avslutning-pa-livet-_sluttra pport.pdf

[10] (2008) ACT 2008-06-20 No. 44: Act on Medical and Health Research (The Health Research Act). 
[11] Esping-Andersen, G. and Korpi, W. (1987) From Poor Relief to Institutional Welfare States: The Development of Scandinavian Social Policy. In: Eriksson, R., Ringen, E. and Uusitalo, H., Eds., The Scandinavian Model: Welfare States and Welfare Research, M.E., Sharpe, New York, 39-74.

[12] Daatland, S.O. and Lowenstein, A. (2005) Intergenerational Solidarity and the Family-Welfare State Balance. European Journal of Ageing, 2, 174-182. http://link.springer.com/article/10.1007\%2Fs10433-005-0001-1\#page-1 http://dx.doi.org/10.1007/s10433-005-0001-1

[13] Kildal, N. and Kuhnle, S. (2005) The Nordic Welfare Model and Universalism. In: Kildal, N. and Kuhnle, S., Eds., Normative Foundation of the Welfare State: The Nordic Experience, Routledge, London, 13-33.

[14] Romøren, T.I., Torjesen, D.O. and Landmark, B. (2011) Promoting Coordination in Norwegian Health Care. International Journal of Integrated Care, 11, e127.

[15] Rostgaard, T. and Szebehely, M. (2012) Changing Policies, Changing Patterns of Care: Danish and Swedish Home Care at the Crossroads. European Journal of Ageing, 2, 101-109. http://dx.doi.org/10.1007/s10433-011-0209-1

[16] McMillian Cancer Support (2014) Can We Live with How We're Dying? Advancing the Case for Free Social Care at the End of Life. http://www.macmillan.org.uk/Documents/GetInvolved/Campaigns/Endoflife/EndofLifereport-June2014.pdf

[17] Statistics of England (2013). http://www.ons.gov.uk/ons/rel/subnational-health1/national-bereavement-survey--voices-/2012/sty-care-at-the-end-of-l ife.html

[18] Gao, W., Ho, Y.K., Verne, J., Glickman, M. and Higginson, I.J. (2013) Changing Patterns in Place of Cancer Death in England: A Population-Based Study. PLoS Medicine, 10, e1001410. http://dx.doi.org/10.1371/journal.pmed.1001410

[19] Aoun, S., Kristjanson, L.J., Currow, D., Skett, K., Oldham, L. and Yates, P. (2007) Terminally-Ill People Living Alone without a Caregiver: An Australian National Scoping Study of Palliative Care Needs. Palliative Medicine, 21, 29-34. http://dx.doi.org/10.1177/0269216306073198

[20] Hanratty, B., Addington-Hall, J., Arthur, A., Cooper, L., Grande, G., Payne, S. and Seymour, J. (2013) What Is Different about Living Alone with Cancer in Older Age? A Qualitative Study of Experiences and Preferences for Care. BMC Family Practice, 14, 22. http://dx.doi.org/10.1186/1471-2296-14-22

[21] Wheatley, V. and Baker, J. (2007) "Please, I Want to Go Home”: Ethical Issues Raised When Considering Choice of Place of Care in Palliative Care. Postgraduate Medical Journal, 83, 643-648. http://dx.doi.org/10.1136/pgmj.2007.058487 http://pmj.bmj.com/content/83/984/643.full.pdf+html

[22] Pedersen, A. (2014) Place of Death-Cancer and Gender. Institute of Public Health, Oslo.

[23] Carlsson, M.E. and Rollison, B. (2003) A Comparison of Patients Dying at Home and Patients Dying at a Hospice: Sociodemographic Factors and Caregivers’ Experiences. Palliative \& Support Care, 1, 33-39. http://dx.doi.org/10.1017/S1478951503030098

[24] Bee, P.E., Barnes, P. and Luker, K.A. (2009) A Systematic Review of Informal Caregivers' Needs in Providing Home-Based End-of-Life Care to People with Cancer. Journal of Clinical Nursing, 18, 1379-1393. http://dx.doi.org/10.1111/j.1365-2702.2008.02405.x

[25] Seow, H., Barbera, L., Howell, D. and Dy, S.M. (2010) Using More End-of-Life Homecare Services is Associated with Using Fewer Acute Care Services: A Population-Based Cohort Study. Medical Care, 48, 118-124. http://dx.doi.org/10.1097/MLR.0b013e3181c162ef

[26] Gott, M., Gardiner, C., Ingleton, C., Cobb, M., Noble, B., Bennett, M.I. and Seymour, J. (2013) What Is the Extent of Potentially Avoidable Admissions amongst Hospital Inpatients with Palliative Care Needs? BMC Palliative Care, $12,9$. http://dx.doi.org/10.1186/1472-684X-12-9

[27] (2008-2009) Report No. 47 to the Storting: The Coordination Reform. Norwegian Minister of Health and Care Services, Oslo. https://www.regjeringen.no/globalassets/upload/hod/dokumenter20info/samhandling-engelsk_pdfs.pdf

[28] Burge, F., Lawson, B., Johnston, G. and Flowerdew, G. (2005) Health Care Restructuring and Family Physician Care for Those Who Died of Cancer. BMC Family Practice, 6, 1. http://www.biomedcentral.com/1471-2296/6/1 http://dx.doi.org/10.1186/1471-2296-6-1

[29] Heedman, P.A. and Strang, P. (2003) Pain and Pain Alleviation in Hospital-Based Home Care: Demographic, Biological and Treatment Factors. Support Care Cancer, 11, 35-40.

[30] Goodwin, L., Price, A., Lee, W., Rayner, L., Moorey, S., Monroe, B. and Hotopf, M. (2014) I’ve Had a Good Life, What's Left Is a Bonus: Factor Analysis of the Mental Adjustment to Cancer Scale in a Palliative Care Population. Palliative Medicine, 28, 243-255. http://dx.doi.org/10.1177/0269216313498435

[31] Fisher, K., Seow, H., Cohen, J., Declercq, A., Freeman, S. and Guthrie, D.M. (2014) Patient Characteristics Associated With Prognostic Awareness: A Study of a Canadian Palliative Care Population Using the InterRAI Palliative Care In- 
strument. Journal of Pain and Symptom Manage, 49, 716-725. http://dx.doi.org/10.1016/j.jpainsymman.2014.08.008

[32] McLeod-Sordjan, R. (2014) Death Preparedness: A Concept Analysis. Journal of Advance Nursing, 70, $1008-1019$. http://dx.doi.org/10.1111/jan.12252

[33] Paulson, S., Kellehear, A., Kripal, J.J. and Leary, L. (2014) Confronting Mortality: Faith and Meaning across Cultures. Annals of the New York Academy of Sciences, 1330, 58-74. http://dx.doi.org/10.1111/nyas.12474 